\title{
Expanding Our Understanding of the Expanded Therapeutic Alliance: Introduction to the Special Issue
}

\author{
Valentín Escudero ${ }^{1} \cdot$ Myrna L. Friedlander ${ }^{2}$ \\ Accepted: 13 October 2021 / Published online: 22 October 2021 \\ (c) The Author(s), under exclusive licence to Springer Science+Business Media, LLC, part of Springer Nature 2021
}

Now that it has become abundantly clear that family members' perceptions and behavioral manifestations of the expanded therapeutic alliance significantly predict clinical progress and effectiveness, researchers are being called upon to advance our knowledge of this critically important common factor by attending to three issues: (1) how alliances develop in particularly challenging therapeutic contexts, such as when the family has a history of relational trauma; (2) how alliances in conjoint therapy are sustained and, when they falter or are "split," how they can be "repaired" or re-balanced so as not to impede therapeutic progress; and (3) how therapists' perspectives on the alliance can be understood alongside (rather than compared to) the alliance perspectives of family members.

This Special Issue advances our knowledge in each of these ways. As a group, the six articles in the Issue address systemic aspects of the developing alliance in terms of selfreported perceptions as well as the behavioral positioning of clients and therapists in relation to their shared working relationship, including how safe each family member feels in the therapeutic space and how well family members are collaborating on setting goals and carrying out therapeutic tasks to address their common understanding of the family's problems. As guest editors of the Special Issue, we have thoroughly enjoyed reading these articles and anticipate that you, as readers of this journal, will concur with us and our invited commentator, Laurie Heatherington, on their value.

Publisher's Note Springer Nature remains neutral with regard to jurisdictional claims in published maps and institutional affiliations.

Myrna L. Friedlander

mfriedlander@albany.edu

Valentín Escudero

valentin.escudero@udc.es

1 Department of Psychology, University of A Coruña, A Coruña, Spain

2 Department of Educational and Counseling Psychology, Albany, NY, USA 